\title{
Stability analysis of apparent resistivity measurement in the seismically active area of Val d'Agri (southern Italy)
}

\author{
M. Balasco ${ }^{1,2}$, V. Lapenna ${ }^{2}$, A. Siniscalchi ${ }^{1}$, and L. Telesca ${ }^{2}$ \\ ${ }^{1}$ Dipartimento di Geologia e Geofisica, Università degli Studi di Bari, Italy \\ ${ }^{2}$ Istituto di Metodologie Analisi Ambientale IMAA-CNR, Tito Scalo (PZ), Italy
}

Received: 21 July 2004 - Revised: 23 November 2004 - Accepted: 24 November 2004 - Published: 26 November 2004

Part of Special Issue "Precursory phenomena, seismic hazard evaluation and seismo-tectonic electromagnetic effects"

\begin{abstract}
A magnetotelluric monitoring station has been installed in the Val d'Agri area (southern Italy), to investigate the physics underlying the generation mechanisms of the electrokinetic effect, due to rapid pore pressure changes and fluid flows near the focal area of incoming earthquakes. It is well known that the magnetotelluric method reveals variations in electrical resistivity within the Earth at large depths, reaching within appropriate frequency bands the Earth's mantle. Depth sounding is performed by measuring the ratio between the mutually perpendicular horizontal electric and magnetic fields at the earth's surface, furnishing the apparent resistivity, which describes the electrical properties of subsoil as function of depth.

The selected site of Val d'Agri has been struck by strong seismic events in past and recent years, this suggesting the investigation of possible changes in apparent resistivity correlated with the local tectonic activity.

We analyzed the stability of the measurement of apparent resistivity and phase of the impedance tensor $Z(\omega)$ during time. Our findings suggest that the measure of apparent resistivity during night-time is more stable. Therefore, we identified the characteristic apparent resistivity curve of the subsoil of the Val d'Agri site, which could be considered as a reference.
\end{abstract}

\section{Introduction}

Co-seismic and pre-seismic anomalous variations in geophysical parameters have been observed and documented. Changes in electric, magnetic and electro-magnetic fields correlated with seismic activity have been reported in USSR (Kopytenko et al., 1993), Greece (Varotsos et al., 1993; Nomikos et al., 1997), China (Zhao et al., 1997), Japan (Molchanov et al., 1998; Nagao et al., 2000), and USA (Mueller and Johnston, 1998); ULF electromagnetic precur-

Correspondence to: L. Telesca

(ltelesca@imaa.cnr.it) sory signs of incoming strong earthquakes have been described by Hayakawa et al. (2000), and possible preseismic geoelectrical changes have been reported by Uyeda et al. (2000). Significant resistivity variations have been observed prior to fault rupture (Park et al., 1993). Researchers from Standford University, California, have installed two electromagnetic (EM) monitoring systems to search possible precursory or co-seismic EM signals associated with large aftershock near the epicenter of the 16 October $1999 \mathrm{Hec}-$ tor Mine earthquake (Karakelian et al., 2002). The analysis carried out by Hayakawa et al. (1996) evidenced anomalous ULF emissions observed few days before the 8 August Guam earthquake $(\mathrm{Ms}=8.1)$.

Variations of magnetic and electric field could be the endproduct of rapid pore pressure changes and fluid flow following rupture within the fault zones. Several mechanisms to explain the generation of electromagnetic anomalous changes have been proposed. Fenoglio et al. (1995) studying the Loma Prieta earthquake (17 October 1987, ML=7.1) invoked electrokinetic effects to justify the strong magnetic field generated at surface. Merzer and Kemplerer (1997) proposed a mechanism for generation of electromagnetic signals which depend on induced electric currents flowing in a fault zone: the increase of the conductivity in the focal area is due to a precursory reorganisation of the geometry of fluid filled porosity in the fault-zone porosity (dilatant-conductivity effect). A model for the generation of the electric current in rocks under stress, involving the strain rate, has been proposed by Tzanis and Vallianatos (2002). On the basis of the laboratory experiments they calculated the deformation rate necessary to generate an electric signal, simulating the propagation of the electric and magnetic fields.

In our study we investigate the Val d'Agri area (southern Italy), which was struck by a strong earthquake in 1857 , $M=7.0$ (Mallet, 1862). The location of the master-fault responsible for the 1857 earthquake is a much-discussed question (Benedetti et al., 1998; Pantosti and Valensise, 2001), although evidences, based on focal plane solutions, suggest a north-eastward dipping fault along the Agri Valley (Cucci 


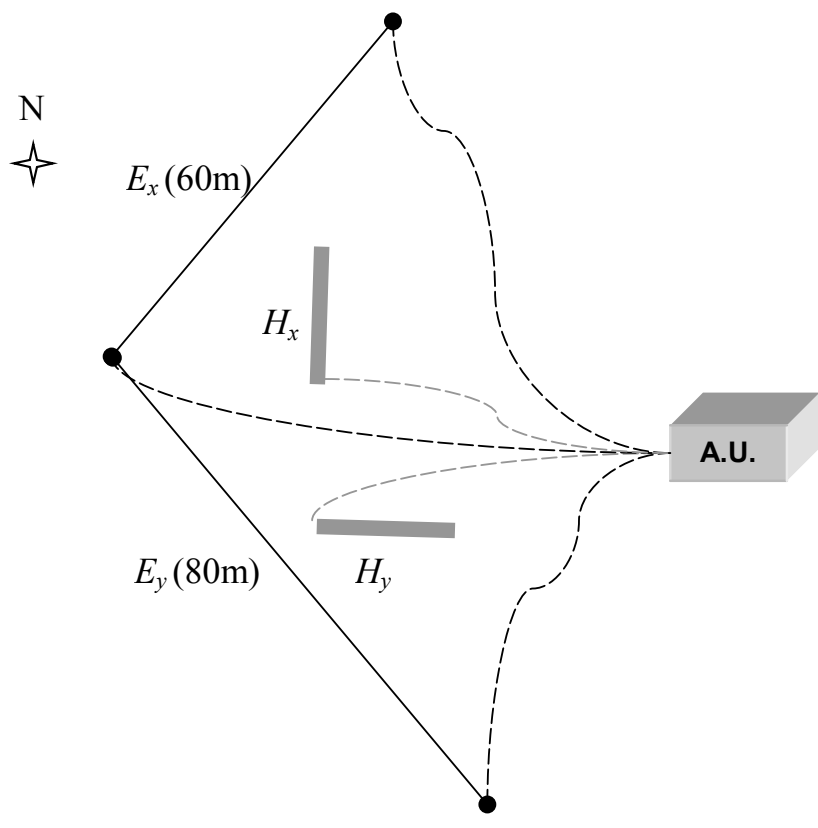

Fig. 1. Configuration of electrical dipoles and magnetic sensors (A.U., Acquisition Unit).

et al., 2004). Therefore, this area is ideal to investigate possible correlations between strong incoming earthquakes and variations in electrical parameters.

To this scope, we installed in this area a magnetotelluric station, which continuously measure electromagnetic field.

The aim of the paper is the stability analysis of the apparent resistivity estimation, and the identification of the characteristic apparent resistivity curve for the investigated site.

\section{Signal detection}

A classical MT sounding consists of simultaneous measurements of electric and magnetic fields to obtain, by means the impedance tensor, the apparent resistivity.

The relationship between electric and magnetic fields as a function of frequency is given by the following tensorial equation (Kaufman and Keller, 1981):

$$
\left|\begin{array}{l}
E_{x}(\omega) \\
E_{y}(\omega)
\end{array}\right|=\left|\begin{array}{ll}
Z_{x x}(\omega) & Z_{x y}(\omega) \\
Z_{y x}(\omega) & Z_{y y}(\omega)
\end{array}\right|\left|\begin{array}{c}
H_{x}(\omega) \\
H_{y}(\omega)
\end{array}\right|,
$$

where $\omega$ is the angular frequency, $E_{x}$ and $H_{x}$ represent the electric and magnetic fields in NS direction, $E_{y}$ and $H_{y}$ the electric and magnetic fields in EW direction.

The apparent resistivity $(\rho)$ and phase $(\phi)$ of the ground are defined by the following equations:

$\rho_{i j}^{a}(\omega)=\frac{1}{\mu_{o} \omega}\left|Z_{i j}(\omega)\right|^{2}$,

$\phi_{i j}=\frac{180}{\pi} \tan ^{-1}\left[\operatorname{Im}\left(Z_{i j}\right) / \operatorname{Re}\left(Z_{i j}\right)\right]$,

where $\mu_{0}$ is the permeability of the vacuum, $\operatorname{Im}\left(Z_{i j}\right)$ and $\operatorname{Re}\left(Z_{i j}\right)$ are the imaginary and real parts of $Z_{i j}$ with $i, j=x$ or $y$.
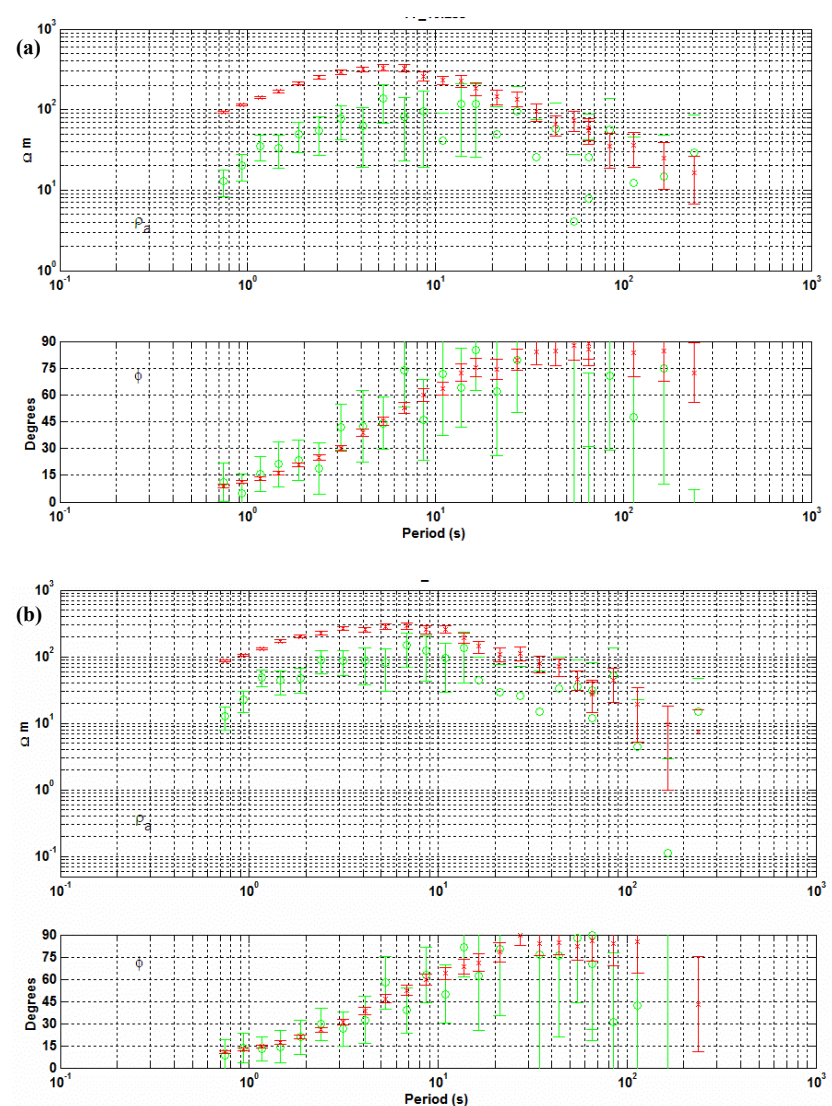

Fig. 2. Apparent resistivity and phase curves recorded during a day (a) and night-time period (b).

As a simple linear system, the transfer function $Z(\omega)$ acts as a filter, while the magnetic and electric fields represent the input and output, respectively.

In noise-free conditions the transfer function should be constant. Therefore it is necessary to perform a continuous MT monitoring, to control the resistivity variations, and thus the impedance variations.

The MT continuous monitoring station used for this study (Fig. 1) is provided with a receiver MT24LF, two induction coils (BF4-EMI Inc.) to measure the N-S $\left(H_{x}\right)$, E-W $\left(H_{y}\right)$ components of the magnetic field and two electric dipoles in the $40^{\circ} \mathrm{N}\left(E_{x}\right)$ and $140^{\circ} \mathrm{N}\left(E_{y}\right)$ directions, respectively, $60 \mathrm{~m}$ and $80 \mathrm{~m}$ long to measure the electric field (Balasco et al., 2004).

Obviously noise affects the measurements of the electric and magnetic fields, thus introducing uncertainties in the estimation of the impedance tensor. This represents a key point in the general framework of the investigation of correlations between fluctuations in apparent resistivity and seismic activity. Thus, we selected the investigated area, because it is relatively noise-free, being far by railways, highway, power lines etc.

In order to really measure earthquake-induced resistivity variations it is necessary to apply robust statistical techniques able to define the stability of the impedance tensor in absence 

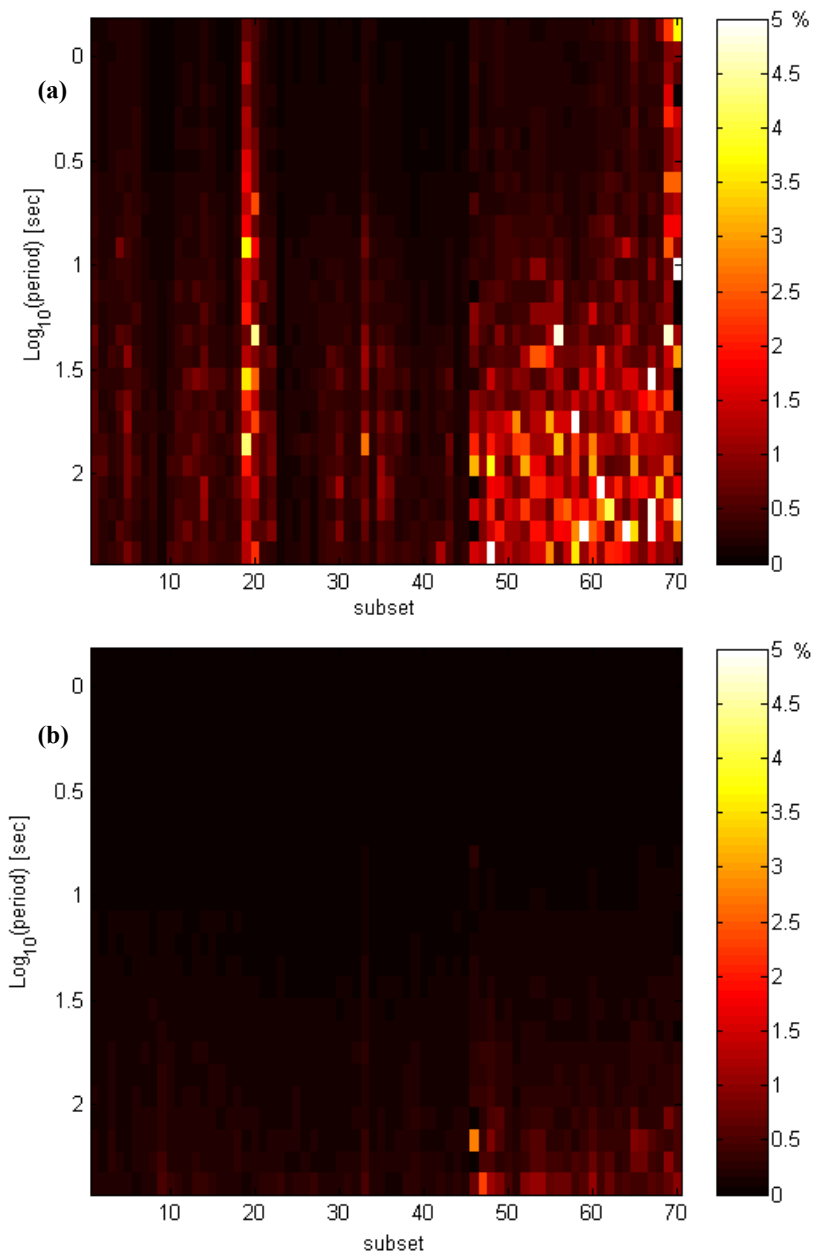

Fig. 3. Standard errors related to each subset for all periods in $\rho_{x y}$ component (a) and $\rho_{y x}$ component (b).

of significant variations in subsoil. And, of course, the e.m. noise represents the main problem, because it acts as an additional field that affects the estimates of $Z$, particularly in our case in which there is only a single station measurement (Eisel and Egbert, 2001).

Our aim is to discriminate an appropriate estimation of the $Z$ that can be adopted satisfying a good signal-to-noise ratio.

\section{Data analysis}

The data set analyzed is from 7 to 29 July 2003. The frequency of data recording was set to $6.25 \mathrm{~Hz}$. The continuous data stream was subdivided into segments of 81750 samples, each segment corresponding to about $3 \mathrm{~h}$ and $38 \mathrm{~min}$ duration. In order to study the influence of possible anthropical noise on the measurements, we analyzed separately the signal measured during day-time and night-time. In Fig. 2 we can observe the curves of apparent resistivity $\left(\rho_{a}\right.$, upper) and phases $(\phi$, down) computed during day-time (Fig. 2a) and night-time (Fig. 2b) of one subset. With the symbol $(o)$, we
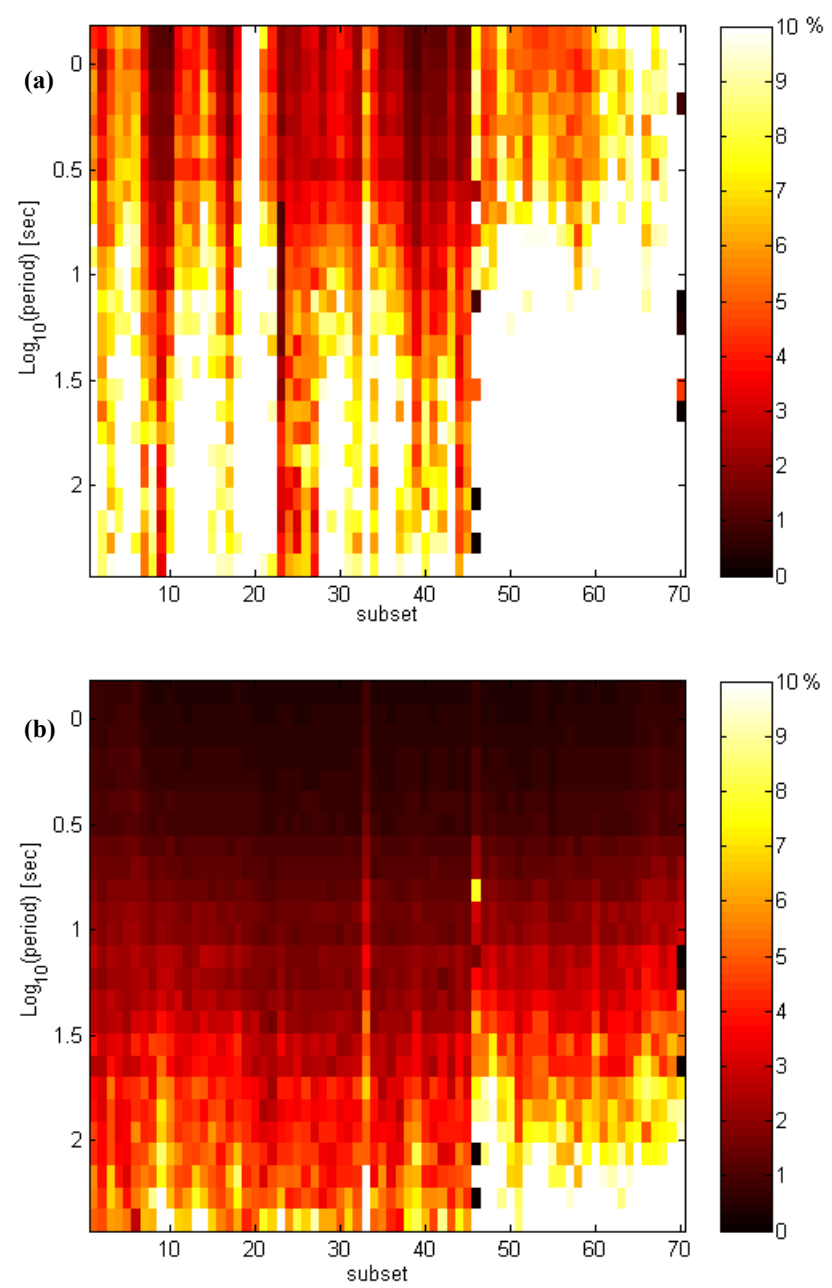

Fig. 4. Standard errors related to each subset for all periods in $\phi_{x y}$ component (a) and $\phi_{y x}$ component (b).

indicate the $x y$ apparent resistivity component whereas the $y x$ apparent resistivity component is denoted by the symbol $(x)$. These curves and the error bars have been obtained using the Transfer Function Estimation Program (tranmt-EMTF), a robust algorithm described in Egbert and Booker (1986). Comparing Figs. $2 \mathrm{a}$ and $2 \mathrm{~b}$ we can observe that the best results are obtained considering only the subsets recorded during night-time, in which the resistivity curves are less biased downward than those calculated for day-time and the phases are stable also at the longest period.

Following Egbert and Eisel (2001), to study the temporal stability of the apparent resistivity, we calculated the median value $(\bar{\rho})$ for each subsets over the frequency range. Figure 3a shows the deviation of the apparent resistivity of each subset from the median normalized by the median (value expressed in percentage) defined by means of the following equations:

$\Delta \rho_{x y}=\frac{\left(\rho_{x y}-\bar{\rho}_{x y}\right)}{\bar{\rho}_{x y}}, \quad \Delta \rho_{y x}=\frac{\left(\rho_{y x}-\bar{\rho}_{y x}\right)}{\bar{\rho}_{y x}}$. 

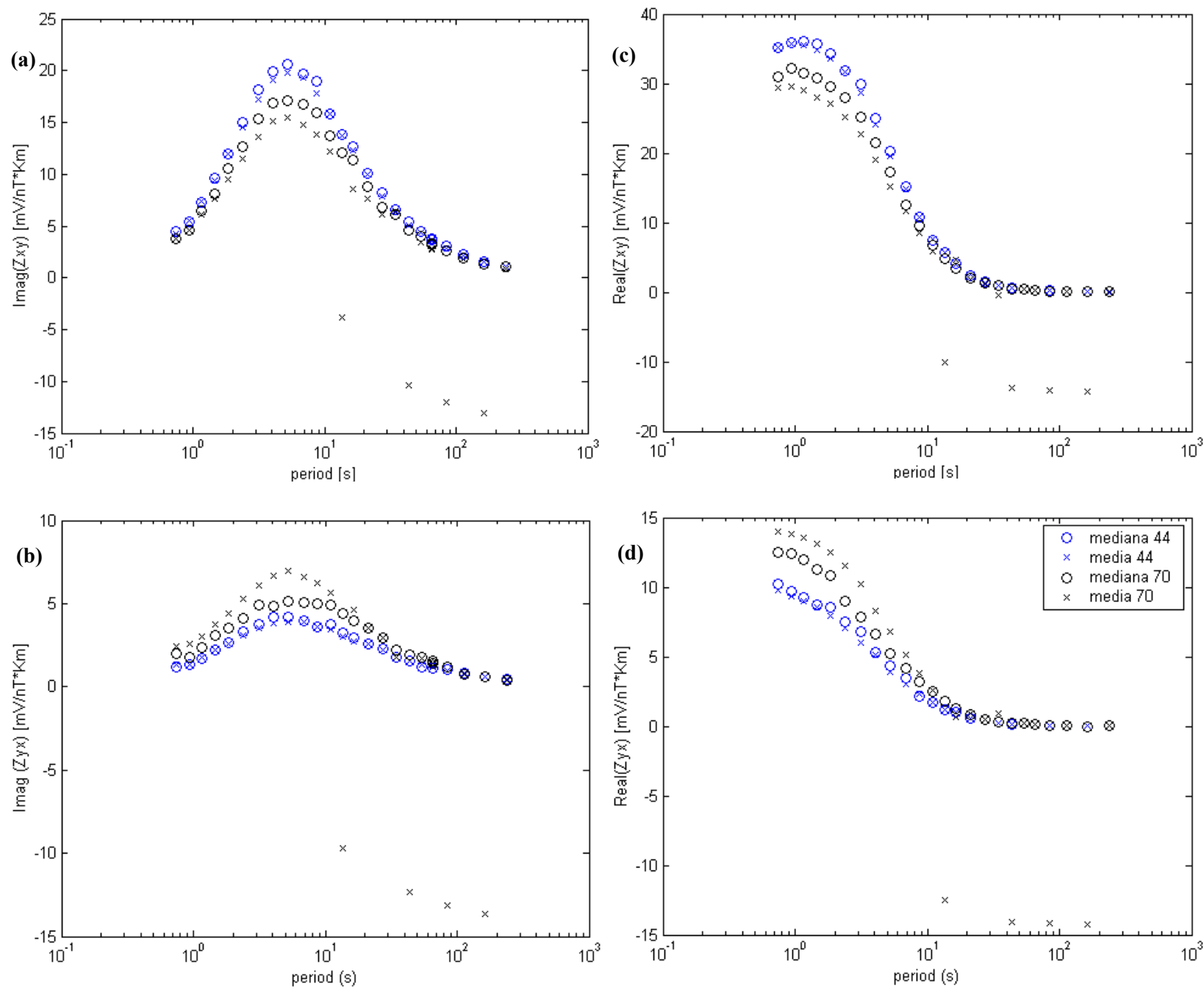

Fig. 5. Imaginary part of the $Z_{x y}$ (a) and $Z_{y x}$ (b) and real part of the $Z_{x y}$ (c) and $Z_{y x}$ (d) computed from the median and the mean values of all and 44 selected subsets.

The phase deviation $\Delta \phi_{x y}=\phi_{x y}-\bar{\phi}_{x y}$ and $\Delta \phi_{y x}=\phi_{y x}-\bar{\phi}_{y x}$, in degrees, are shown in Fig. 4. As discussed in Egbert and Eisel (2001), we can compare $\Delta \phi$ and $\Delta \rho$ to identify regions more affected by noise. From Figs. 3 and 4 we can assert that only the $x y$ component is particularly affected by noise, more evident at high frequencies and especially in the phase.

To better investigate the character of the noise in $x y$ component, we estimated the mean and median of the real and imaginary parts of the $Z$ tensor. If the errors in the $Z$ estimate are gaussianly distributed, the errors in real and imaginary parts should be equally distributed. From a comparison of all the subsets, we selected those with higher $\mathrm{S} / \mathrm{N}$ ratio (44 subsets). We found that the mean and the median among the selected subsets of the real and imaginary part of the $Z$ tensor are almost identical (Fig. 5). This means that the assumption of independent and identically distributed Gaussian errors is satisfied and the least square-based estimate of the impedance tensor is then justified.
Considering only the 44 selected subsets we obtain an improvement of the $Z$ stability more evident in imaginary part of $Z$ (Fig. 5a, and 5b).

Goldstein and Strangway (1975) discussed about the use of a controlled source in magnetotelluric method. For measurements carried out near the source (inside three skin depths), the resistivities obtained are in disagreement with the true values. The presence of a near and intermittent field source causes an increase of real part respect to imaginary part of the impedance, which corresponds to a tendency to zero of the phase. Figure 6 displays the median of the phase for all the subsets; it is visible a decrease of the phase at long periods.

Therefore, we can assert that in the Val d'Agri area an intermittent noise source, added to natural electromagnetic field, is probably present. This noise affects the measurements particularly during day-time, and it modifies considerably only the $x y$ component, allowing to suppose that noise 


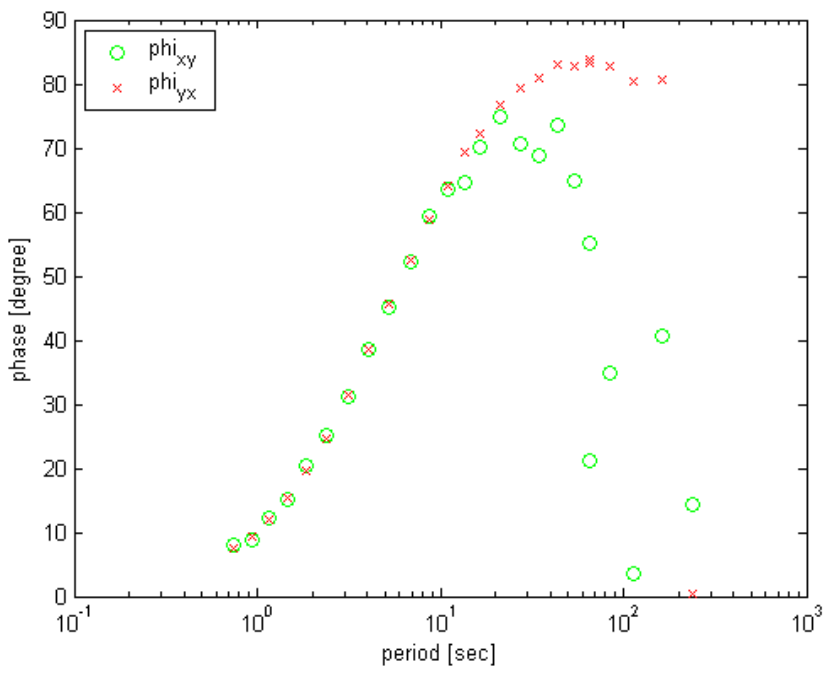

Fig. 6. Phase curves computed from the median of all subsets.

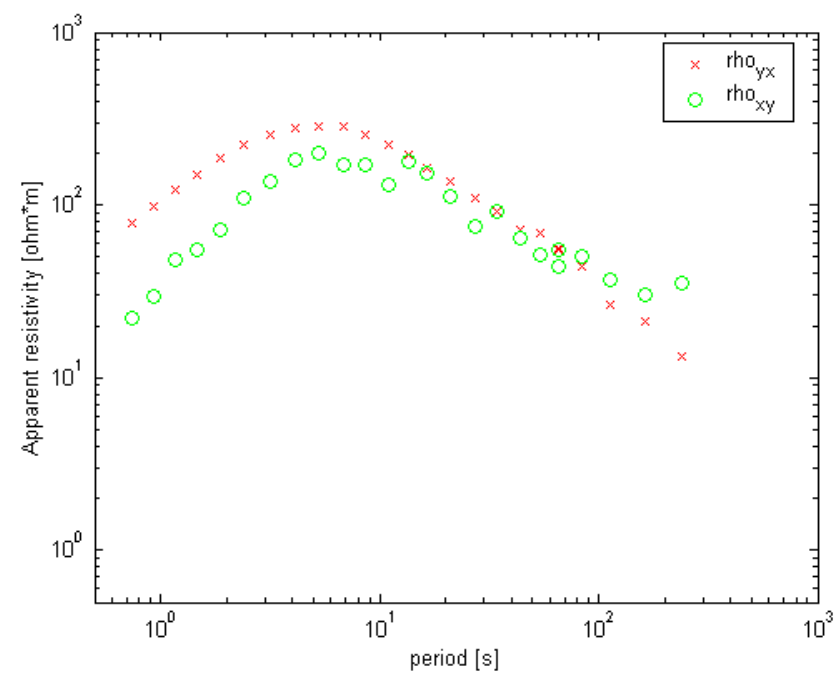

Fig. 7. Apparent resistivity curves computed from the median values for night-time subsets.

source is polarized in this direction. We can conclude that, even without a remote station, we are able to characterize the noise in our site and to define the characteristic apparent resistivity curve of the Val d'Agri site. Figure 7 shows the apparent resistivity curves computed from the median of the night-time subsets. In particular we consider primarily, at this stage, the $y x$ component because it reveals a major stability and allows us to evaluate, in the future, if significant apparent resistivity changes could be connected to local seismic activity.

The geological structure of the Agri Valley is very complex as shown by a lot of publications about it (Cello et al., 2000; Rizzo et al., 2002).

The near-surface conductivity heterogeneities can distort the interpretation of the MT data. The traditional approach to this difficulty (Swift, 1967) is to assume a simplified 2$\mathrm{D}$ conductivity model for which the conductivity varies with

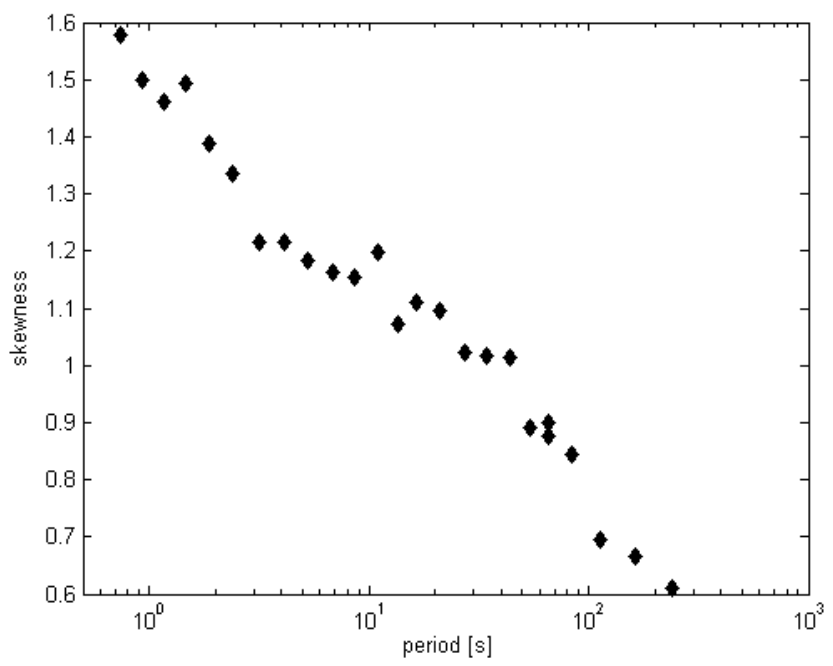

Fig. 8. Skewness versus period for the Agri Valley site.

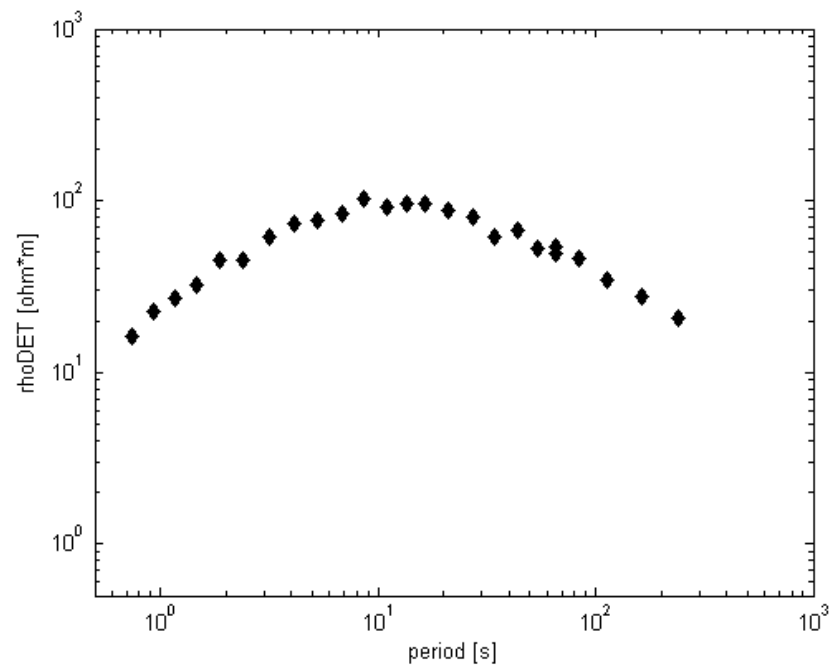

Fig. 9. Determinant of $Z$ versus period for the Agri Valley site.

depth and one horizontal direction, but the conductivity is constant in the other direction. For an appropriate selection of the reference axes (in the 2-D strike coordinate system) the diagonal elements of $Z$ vanish. In a general 3-D case, all elements of the $Z$ are used to describe the deviation of the conductivity distribution from the exact $2-\mathrm{D}$ case. In this case we obtain an improvement in understanding the experimental magnetotelluric data (Bahr, 1991).

An non-dimensional rotational invariant parameter which measures the departure from an ideal 2-D model is the skewness given by Swift (1967):

$s=\frac{\left|Z_{x x}+Z_{y y}\right|}{\left|Z_{x y}-Z_{y x}\right|}$.

Figure 8 shows the skewness parameter versus period for our investigated site. At longest periods the conductivity 
distribution approaches to 2-D: in fact the main diagonal elements, $Z_{x x}$ and $Z_{y y}$, tend to vanish.

In a previous paper (Balasco et al., 2004) we considered the departure from the 2-D model at short period and evaluated the electrical and magnetic distortion in the tensor impedance and, by application of Mohr analysis (Lilley, 1998), we found at the longest periods a clear relationship between the magnetic-axis strike (about $-50^{\circ}$ ) and the presumable regional geological strike, the Apenninic trend. In particular it is almost perpendicular to the $\mathrm{x}$ direction of the electric lines, respect to which apparent resistivities were estimated: it means that the estimated $x y$ component represents the TM mode and the $y x$ the TE one. The Agri Valley is a NW-SE intermontane basin filled by middle Pleistocene alluvial deposits (Di Niro and Giano, 1995). Our MT station is located on NE valley border, limited to South from the Pleistocenic deposits and to North from the limestones of the Lagonegro Unit. Moreover to better understand the resistivity variation in depth we calculate the determinant of $Z$ which has the advantage to be less influenced by shallow conductive lateral bodies like the Val d'Agri sediments filling the basin (Ingham, 1988). Figure 9 shows the behaviour of the $Z$ determinant versus period, that reveals the same shape as observed in Fig. 7, thus confirming a consistence of the results.

\section{Conclusions}

In this paper we perform a detailed statistical analysis of apparent resistivity data recorded in Val d'Agri area, to evaluate the stability of the estimate of the impedance tensor. We found that they are more stable during night-time recording, due to the reduction of anthropic noise sources. Furthermore, we have proved that is possible to select a subset for which the statistical fluctuations of the estimates in time reflects Gaussian criteria of error distribution. A relative instability on the $Z$ estimates is mainly associated to $x y$ component suggesting the presence of a polarised noise source.

Therefore we can consider mainly the $y x$ component apparent resistivity computed from median values as a reference for further study.

Moreover, in the next future we will install another station to better control the noise in our signal and to take into account the geological complexity. Further we will carried out a MT survey across to Agri Valley in order to see if the results related to the stability and behaviour are persistent all over area.

Edited by: P. F. Biagi

Reviewed by: K. Hattori and F. Vallianatos

\section{References}

Bahr, K.: Geological noise in magnetotelluric data - A classification of distortion types, Phys. Earth Plan. Int., 66, 1-2, 24-38, 1991.

Balasco, M., Colangelo, G., Lapenna, V., Loddo, M., Siniscalchi, A., and Telesca, L.: Measuring apparent resistivity in a seismically active area of Southern Italy, Phys. Chem. Earth, 29, 4-9, 329-337, 2004.

Benedetti, L., Tapponnier, P., King, G. C. P., and Piccardi, L: Surface Rupture of the 1857 Southern Italian earthquake, Terra Nova, 10, 4, 206-210, 1998.

Cello, G., Gambini, R., Mazzoli, S., Read, A., Tondi, E., and Zucconi V.: Fault zone characteristics and scaling properties of the Val d'Agri Fault System (Southern Appennines, Italy), J. Geodyn., 29, 293-307, 2000.

Cucci, L., Pondrelli, S., Frepoli, A., Mariucci, M. T., and Moro, M.: Local pattern of stress field and seismogenic sources in the Pergola-Melandro basin and the Agri valley (Southern Italy), Geophys. J. Int., 156, 3, 575-583, 2004.

Di Niro, A. and Giano, S. I.: Evoluzione geomorfologica del bordo orientale dell'alta val d'Agri (Basilicata) Studi Geologici Camerti, 2, 207-218, 1995.

Egbert, G. D. and Booker, J. R.: Robust estimation of geomagnetic transfer functions, Geophys. J. R. Astr. Soc., 87, 173-194, 1986.

Eisel, M. and Egbert, G. D.: On the stability of magnetotelluric transfer function estimates and the reliability of their variances, Geophys. J. Int., 144, 65-82 2001.

Fenoglio, M. A., Johnston, M. J. S., and Byerlee, J. D.: Magnetic and electric fields associated with changes in high pore pressure in fault zones: Applied to the Loma Prieta ULF emissions, J. Geophys. Res. Sol. Earth., 100, 12 951-12 958, 1995.

Gallipoli, M., Albarello, D., Calvano, G., Lapenna, V., and Mucciarelli M.: Stime sulla pericolosità sismica e misure di amplificazione locale relative ai centri urbani dell'Alta Val d'Agri, Ingegneria Sismica, 3, 59-71, 1998.

Goldstein, M. A. and Strangway, D. W.: Audio-Frequency Magnetotellurics with a grounded Electric Dipole Source, Geophysics, 40, 4, 669-683, 1975.

Hayakawa, M., Kawate, R., Molchanov, O. A. and Yumoto, K.: Results of ultra-low-frequency magnetic field measurements during the Guam earthquake of 8 August 1993, Geophys. Res. Lett., 23, 3, 241-244, 1996.

Hayakawa, M., Hattori, K., Itoh, T., and Yumoto, K.: ULF electromagnetic precursors for an earthquake at Biak, Indonesia on 17 February 1996, Geophys. Res. Lett., 27, 10, 1531-1534, 2000.

Ingham, M. R.: The use of invariant impedances in magnetotelluric interpretation, Geophys. J. Int., 92, 165-169, 1988.

Karakelian, D., Beroza, G. C., Klemperer, S. L., and Fraser-Smith, A. C.: Analysis of ultralow-frequency electromagnetic field measurements associated with the 1999 M 7.1 Hector Mine, California, earthquake sequence, Bulletin of the Seismological Society of America, 92, 4, 1513-1524, 2002.

Kaufman, A. A. and Keller, G. V.: The magnetotelluric sounding method, Elsevier Scientific Publishing Company, Amsterdam, 595, 1981.

Kopytenko, Yu. A., Matiashvily, T. G., Voronov, P. M., Kopytenko, E. A., and Molchanov, O. A.: Detection of ULF emission connected with the Spitak earthquake and its aftershock activity based on geomagnetic pulsations data at Dusheti and Vardziya observatories, Phys. Earth Plan. Int., 77, 85-95, 1993. 
Lilley, F. E. M. (Ted): Magnetotelluric tensor decomposition: Par I, Theory for a basic procedure, Geophysics, 63, 6, 1885-1897, 1998.

Mallet, R.: The first principle of observational seismology as developed in the report to the Royal Society of London of the expedition made by command of the Society into the interior of the Kingdom of Naples to investigate the circumstances of the great earthquake of December 1857, London, 1862, (Reprint Istituto Nazionale di Geofisica, Roma, 1987).

Merzer, M. and Klemperer, S. L.: Modeling low-frequency magnetic-field precursors to the Loma Prieta earthquake with a precursory increase in fault-zone conductivity, Pure Appl. Geophys., 150, 217-248, 1997.

Molchanov, O. A., Hayakawa, M., Odoh, T., and Kawai, E.: Precursory effects in the subionospheric VLF signals for the Kobe earthquake, Phys. Earth Planet. Inter., 105, 239-248, 1998.

Nagao, T., Orihara, Y., Yamaguchi, T., Takahashi, I., Hattori, K., Noda, Y., Sayanagi, K., and Uyeda, S.: Co-seismic geoelectric potential changes observed in Japan, Geophys. Res. Lett., 27, 1535-1538, 2000.

Park, S. K., Johnston, M. J. S., Madden, T. R., Morgan, F. D., and Morrison, H. F.: Electromagnetic precursors to earthquakes in the ULF band; a review of observations and mechanism, Rev. Geophys., 31, 117-132, 1993.
Rizzo, E., Piscitelli, S., Colella, A., and Lapenna, V.: Deep Electrical Resistivity Tomographies to investigate the pre-Quaternary bedrock in the Agri Valley, Southern Italy. European Association of Geoscientists \& Engineers (EAGE), Florence, Italy, 2730 May 2002.

Swift, C. M.: A magnetotelluric investigation of an electrical conductivity anomaly in the South Western United Sates, Ph.D. Thesis, M.I.T., Cambridge, MA, 1967.

Tzanis, A. and Vallianatos, F.: A physical model of electrical earthquake precursors due to crack propagation and the motion of charged edge dislocations, in "Seismo Electromagnetics (Lithosphere-Atmosphere-IonosphereCoupling)" by TERRAPUB, 2002.

Uyeda, S., Nagao, T., Orihara, Y., Yamaguchi, T., and Takahashi, I.: Geoelectric potential changes: Possible precursors to earthquakes in Japan, Proc. US Nat. Acad. Sci., 97, 4561-4566, 2000.

Valensise, G. and Pantosti, D.: Database of Potential Sources for Earthquakes Larger than M 5.5 in Italy, Annali di Geofisica, Suppl. to vol. 44, 4, 180, 2001.

Varotsos, P., Alexopoulos, K., and Lazaridou, M.: Latest aspects of earthquake prediction in Greece based on seismic electric signals, II, Tectonophysics, 224, 1-37, 1993.

Zhao, Y., Zhao, B., and Quian, F.: Electrical streaming potential precursors to catastrophic earthquakes in China, Annali di Geofisica, 40, 2, 241-250, 1997. 